\title{
EVALUATION OF THE EFFICACY OF TOPICAL PIPERINE OIL COMBINED WITH EXCIMER LIGHT PHOTOTHERAPY IN THE TREATMENT OF NON-SEGMENTAL VITILIGO: COMPARATIVE INTRA INDIVIDUAL STUDY
}

\author{
By

\section{Mahmoud Abd El-Ghany El-Dyasty, Mohamed Ahmed Abd El-Rahman El-Khalawany and Ibrahim Mohamed Abd El-Salam Abd El-Kareem}

Department of Dermatology, Venereology and Andrology, Faculty of Medicine, Al-Azhar University

Corresponding Author: Mahmoud Abdel Ghany Eldyasty,

Phone: +201095614391, E-mail: mahmoudddyasty2013@gmail.com

\begin{abstract}
Background: Vitiligo is an acquired idiopathic disease that appears as skin depigmented patches due to a loss of melanocytes that are responsible for producing melanin pigment in the skin, hair, mucous membranes and retina.

Objective: To evaluate the efficacy of topical piperine oil combined with excimer light phototherapy in the treatment of non-segmental vitiligo: comparative intra individual study.

Patients and methods: Our study was carried out on 30 patients complaining of vitiligo from December 2019 to September 2020. Thirty subjects with two comparable patches were treated by excimer light phototherapy; one of them was randomly selected and treated with daily topical piperine oil at home. Patients were selected from out-patient clinic of Dermatology, Venereology and Andrology Department of Al-Azhar University Hospitals.

Results: The present study showed improvement in patches treated with piperine plus excimer light phototherapy as excellent response in $60 \%$ of patients, good response in $6.6 \%$ of patients, fair response in $26.6 \%$ of patients and poor response in $6.6 \%$ of patients. Improvement in patches treated with excimer light phototherapy only as excellent response in $6.6 \%$ of patients, good response in $46.6 \%$ of patients, fair response in $26.6 \%$ of patients and poor response in $20 \%$ of patients.
\end{abstract}

Conclusion: Using piperine combined with Excimer light phototherapy was a promising method for vitiligo treatment.

Keywords: Piperine oil, Excimer light phototherapy, Vitiligo.

\section{INTRODUCTION}

Vitiligo is an acquired idiopathic disease that appears as skin depigmented patches, and its prevalence varies from $1 \%$ to $4 \%$ in different parts of the world and affects all races; moreover, it is more common among people with autoimmune diseases and children whose parents are suffering from this disease (Khaitan et al., 2012). About $30 \%$ to $40 \%$ of the patients have positive family history, equally involving women and men (Mahajan et al., 2015). 
Vitiligo has significant effects on the quality of life, self-esteem, marriage, and employment, especially for people with darker skins and/ or living in countries with different cultures (Whitton et al., 2011). Skin depigmentation in this disorder occurs due to a loss of melanocytes that are responsible for producing melanin pigment in the skin, hair, mucous membranes, and retina, in which several irregular white patches appear on different parts of the skin. In general, the primary patches are formed in sun-exposed sites, mostly including face and dorsal hands (Yaghoobi et al., 2011).

Although the exact mechanism of vitiligo is not well known, several hypotheses for etiology of the disease such as autoimmune, genetic, neural, biochemical, and self-destruction have been postulated (Hedayat et al., 2016). Generally, response to treatment of vitiligo depends on the extent and distribution pattern of the disease; instantly, the patches on head and neck usually show better response to treatment in contrast to the patches located in genital area (Sarveswari, 2010).

Current treatments including topical steroids and calcineurin inhibitor, Phototherapy using NBUVB and excimer light phototherapy are available for this disease. Among them, NBUVB is considered as the treatment with more efficiencies and minimum side effects (Speeckaert and Van, 2017).

Immunological interventions using levamisole, isoprinosine, and topical tacrolimus are also another options. Moreover, surgical methods including full-thickness punch and split-thickness grafts, transplant of melanocyte- keratinocyte cultured suspension, and transplantation of pure melanocyte cultured suspension have been performed as well (Hossan et al., 2012).

In addition to the aforementioned methods, another material, which has been rarely considered and investigated on the skin pigmentation, is piperine, an alkaloid derived from black pepper extract. Based on animal and human studies, piperine has been found to have immunomodulatory, antioxidant, anti-inflammatory and anti-ulcer (Meghwal and Goswami, 2013).

The present work aimed to evaluate the efficacy of topical piperine oil combined with excimer light phototherapy in the treatment of non-segmental vitiligo.

\section{PATIENTS AND METHODS}

This study was carried out on a total of 30 patients with vitiligo from December 2019 to September 2020. The patients were diagnosed by typical clinical findings. The patients were able to read and give consents. Patients under any other treatment modalities, with extensive vitiligo, age less than 6 years, patient with autoimmune diseases as alopecia aerate, breast feeding, patients sensitive to pepper, and history of treatment with NBUVB or topical medications in the last 2 weeks were excluded.

Patients were selected from out-patient clinic of Dermatology, Venereology and Andrology Department of Al-Azhar University Hospitals.

All patients were subjected to complete medical history, dermatological examination and documented digital photography. Thirty subjects with two comparable patches were treated by 
excimer light phototherapy; one of them was randomly selected and treated with daily topical piperine oil at home.

\section{Response to treatment:}

i. Excellent response: $75 \%$ repigmentation or more.

ii. Good response: $50 \%$ regimentation or more.

iii. Fair response: $25 \%$ repigmentation or more. iv. Poor response: less than $25 \%$ repigmentation.

\section{Statistical analysis:}

Results of the present study were statistically analyzed using SPSS 25 (IBM, USA). Data were represented as median \pm SD or number and percentage. Numerical data were compared using Mann-Whitney U test, while categorical data were compared using Chi-square test as appropriate. $\mathrm{P}$ value $<0.05$ was considered significant.

\section{RESULTS}

There was a statistical significant difference between studied patches as regard improvement grades and score (Table 1).

Table (1): Comparison between studied patches as regard improvement

\begin{tabular}{|c|c|c|c|c|c|c|}
\hline \multicolumn{2}{|l|}{ Paramaters } & \multicolumn{2}{|c|}{$\begin{array}{c}\text { Patch A } \\
\text { (piperine/ } \\
\text { excimer) } \\
(\mathbf{N}=\mathbf{3 0}) \\
\end{array}$} & \multicolumn{2}{|c|}{$\begin{array}{l}\text { Patch B } \\
\text { (piperine only) } \\
(\mathbf{N}=\mathbf{3 0})\end{array}$} & P-value \\
\hline \multirow{4}{*}{$\begin{array}{c}\text { Improvement } \\
\text { grades }\end{array}$} & Poor & 2 & $6.7 \%$ & 6 & $20 \%$ & \multirow{4}{*}{$<0.001$} \\
\hline & Fair & 8 & $26.7 \%$ & 8 & $26.7 \%$ & \\
\hline & Good & 2 & $6.7 \%$ & 14 & $46.7 \%$ & \\
\hline & Excellent & 18 & $60 \%$ & 2 & $6.7 \%$ & \\
\hline \multirow{2}{*}{$\begin{array}{l}\text { Improvement } \\
\text { score }\end{array}$} & Mean \pm SD & \multicolumn{2}{|c|}{$64.3 \pm 27.7$} & \multicolumn{2}{|c|}{$43.2 \pm 20.5$} & \multirow{2}{*}{0.002} \\
\hline & Median & \multicolumn{2}{|c|}{77.5} & \multicolumn{2}{|c|}{47.5} & \\
\hline
\end{tabular}

There was a statistically significant difference between studied patches as regard patient satisfaction (Table 2).

Table (2): Comparison between studied patches as regard patient satisfaction

\begin{tabular}{|c|c|c|c|c|c|c|}
\hline \multirow{2}{*}{ Groups } & \multicolumn{2}{|c|}{$\begin{array}{c}\text { Patch A } \\
\text { (piperine/ } \\
\text { excimer) } \\
\text { Patient satisfaction }\end{array}$} & \multicolumn{2}{|c|}{$\begin{array}{c}\text { Patch B } \\
\text { (Piperine only) } \\
(\mathbf{N = 3 0})\end{array}$} & \multirow{2}{*}{ P-value } \\
\hline \multirow{3}{*}{$\begin{array}{c}\text { Patient } \\
\text { satisfaction }\end{array}$} & Poor & 4 & $13.3 \%$ & 7 & $23.3 \%$ & \\
\cline { 2 - 6 } & Fair & 5 & $16.7 \%$ & 11 & $36.7 \%$ & \multirow{2}{*}{$\mathbf{0 . 0 3 4}$} \\
\cline { 2 - 6 } & Good & 7 & $23.3 \%$ & 8 & $26.7 \%$ & \\
\cline { 2 - 6 } & Excellent & 14 & $46.7 \%$ & 4 & $13.3 \%$ & \\
\hline
\end{tabular}




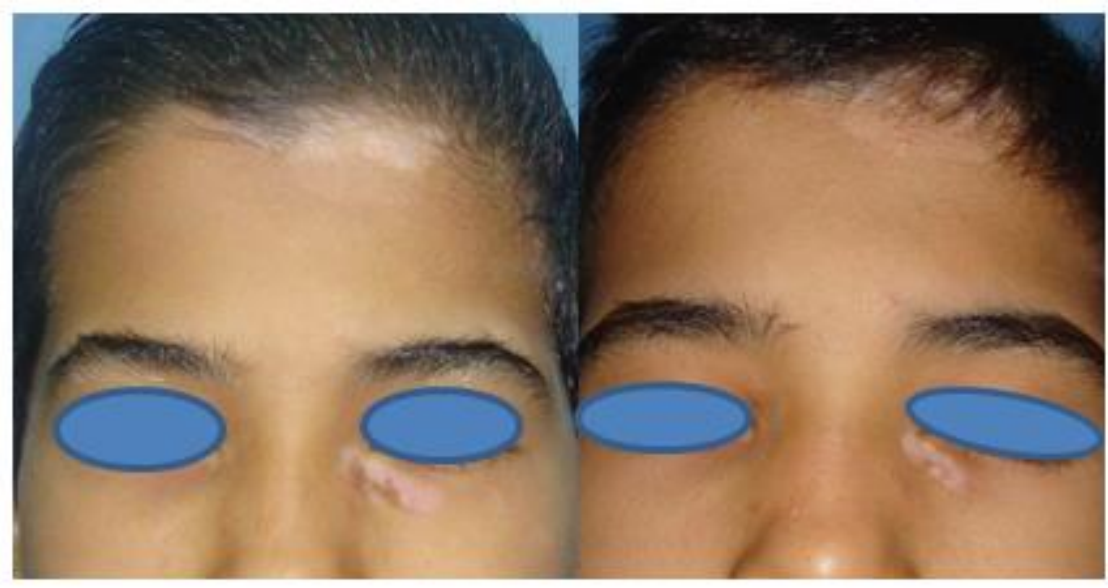

Before

After

Figure (1): A 12 years old male with facial vitiligo before and after treatment showing improvement in patch A (upper one $85 \%$ ) and in patch B (lower one 50\%) after 3 months of treatment

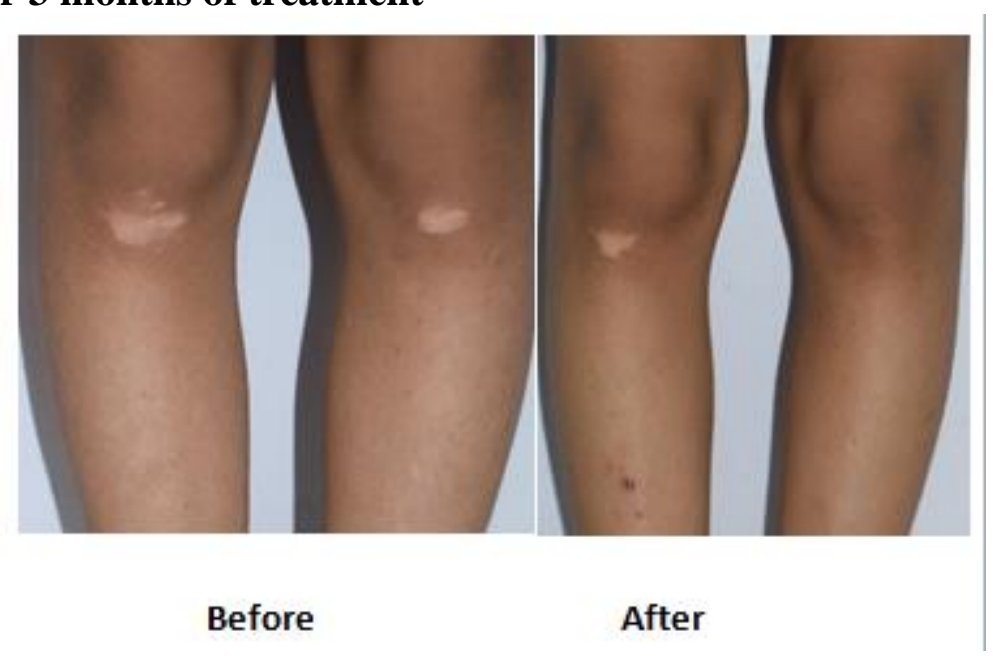

Figure (2): A 15 years old male with knee vitiligo before and after treatment showing improvement in patch A (right side $95 \%$ improvement) and patch B (left side $65 \%$ improvement) after 3 months of treatment.

\section{DISCUSSION}

Vitiligo is a chronic and treatment resistant disease that various therapies have been carried out to obtain repigmentation. Although corticosteroids usually prescribed in treatment of vitiligo, their long term use results in several side effects such as atrophy. Also, tacrolimus (Protopic) has been applied to treat vitiligo that may develop skin cancer or lymphoma (Lee et al., 2010). Due to these adverse side effects for the chemical drugs in treatment of vitiligo, the herbal extracts can appropriate candidates for substitution.

This study, as a clinical trial was the first effort conducted on treatment of vitiligo using piperine as an herbal extract on the basis of the study conducted by Shafiee et al. (2018). 
The results showed that the patients treated with topical piperine/excimer light phototherapy had remarkable repigmentation more than the patients treated with excimer light phototherapy alone. Although the irritation and redness have been seen in the group treated with topical piperine, these observations were temporary and eliminated by using zinc oxide ointment.

Nevertheless, the repigmentation of the group treated with piperine/excimer light phototherapy (case) provided faster trend along with outstanding improvement than excimer light phototherapy alone (control). The combination therapy with piperine and Excimer light phototherapy could predominantly expedite the treatment of vitiligo. It is worth noting that by increasing the repigmentation process, a decrease in treatment sessions of excimer light phototherapy was occurred followed by a decline in the adverse side effects. In a similar work, Nordal et al. (2011) used NB-UVB/Protopic for treatment of vitiligo and compared their results with placebo ointment. The outcomes showed that NBUVB/Protopic had higher reduction in vitiligo patches compared with placebo.

So, using piperine with respect to tacrolimus combined with excimer therapy led to acceptable results with fewer side effects.

\section{CONCLUSION}

Use piperine as a herbal extract in addition to Excimer light phototherapy as a standard method of vitiligo treatment in human subject.
Conflicts of interest: No conflicts of interest were encountered.

\section{REFERENCES}

\section{Hedayat, K., Karbakhsh, M, Ghiasi M, Goodarzi A, Fakour Y, Akbari Z (2016): Quality of life in patients with vitiligo and vitiligo hypotheses: A cross- sectional study based on Vitiligo Quality of Life index (VitiQoL). Health and Quality of Life Outcomes, 14(1): 86-98.}

2. Hossan, Piccinno R, Caccialanza $M$ and Forti $S$ (2012): Narrowband ultraviolet B phototherapy and immunological interventions in the treatment of vitiligo: Evaluation of results in 28 patients. Pediatric Dermatology, 29(2): 160-165.

3. Khaitan B, Kathuria S and Ramam M (2012): A descriptive study to characterize segmenta and nonsegmental vitiligo prevelance. Indian Journal of Dermatology, Venereology and Leprology, 78(6): 715-734.

\section{Lee D, Patel R, Chaudhary B, Mehta} A and Pilani A (2010): tacrolimus (Protopic) has been applied to treat vitiligo that may develop skin cancer or lymphoma, 39(3): 143-146.

5. Mahajan V, Khatri G, Singh R, Chauhan $P$ and Mehta $K$ (2015): Bier spots: An uncommon cause of mottled skin. Indian Dermatol Online J, 6(2): 128-129.

6. Meghwal M and Goswami T (2013): Piper nigrum and piperine: An update. Phytotherapy Research, 27(8): 11211130.

7. Nordal E, Guleng $\mathbf{G}$ and Rönnevig J (2011): Treatment of vitiligo with 
narrowband-UVB (TL01) combined with tacrolimus ointment $(0.1 \%)$ vs. placebo ointment, a randomized right/left double-blind comparative study. Journal of the European Academy of Dermatology and Venereology, 25(12): 1440-1443.

8. Sarveswari K (2010): Cosmetic camouflage in vitiligo and response to treatment. Indian Journal of Dermatology, 55(3): 211-214.

9. Shafiee B, Sun Y, Chen $H$, and Gao, $X$ (2018): Treatment of vitiligo with NB-UVB: A systematic review. Journal of Dermatological Treatment, 26(4): 340-346.

10. Speeckaert $R$ and van $N$ (2017): Vitiligo: An update on pathophysiology and treatment options. American Journal of Clinical Dermatology, 18(6): 733744.

11. Whitton, Toossi P, ShahidiDadras M, Mahmoudi $M$ and Fesharaki R (2011): Effect of vitiligo on the quality of life. Journal of the European Academy of Dermatology and Venereology, 25(10): 1182-1186.

12. Yaghoobi $R$, Omidian $M$ and Bagherani N (2011): Vitiligo: A review of the published work. The Journal of Dermatology, 38(5): 419431. 


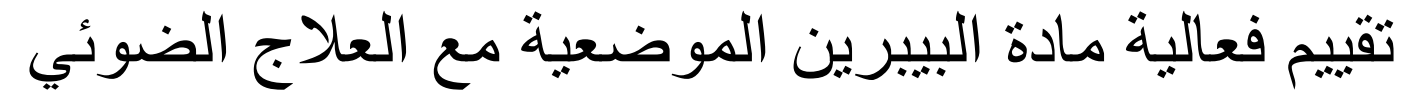

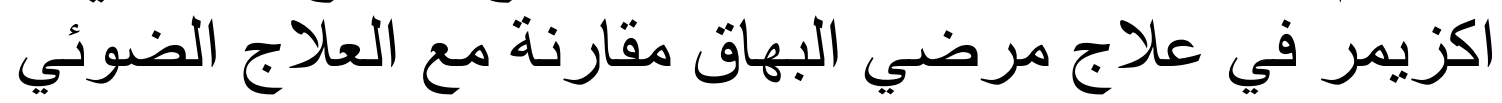

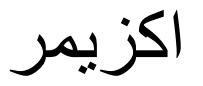

محمود عبد الغنى الايسطي، محمد أحمد عبد الرحمن الخلواني، إبراهيم محمد عبد السلام عبد الكريم

قسم الأمراض الجلدية والتناسلية وأمراض الأكورة، كلية الطب، جامعة الأزهر

E-mail: mahmoudddyasty2013@gmail.com

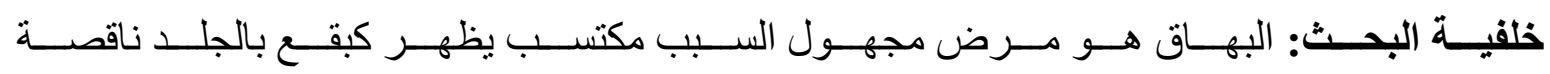

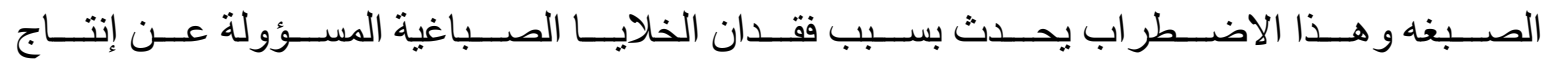

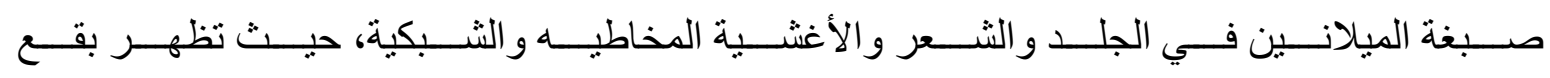
بيضاء على أجز اء مختلفة من الجلد.

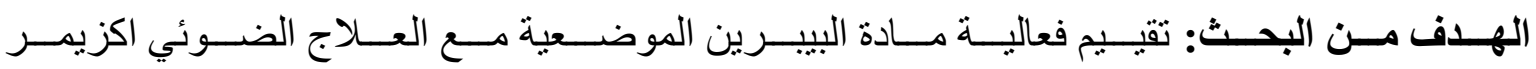
في علاج البهاق مقارنة مع العلاج الضوئي اكزيمر.

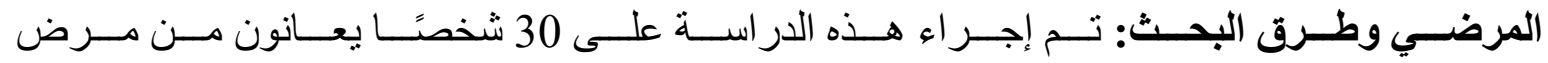

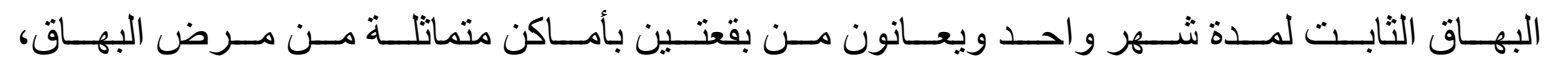

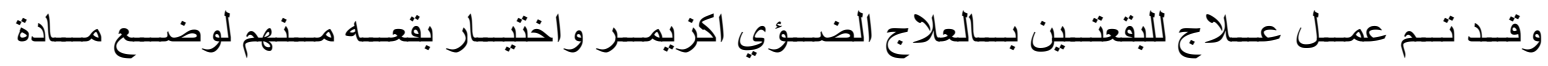
البييرين بالمنزل يوميا.

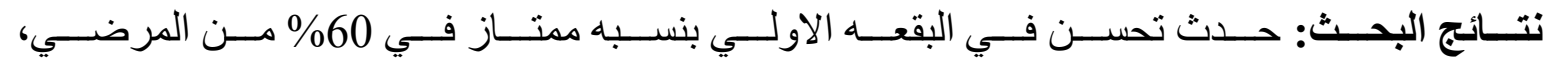

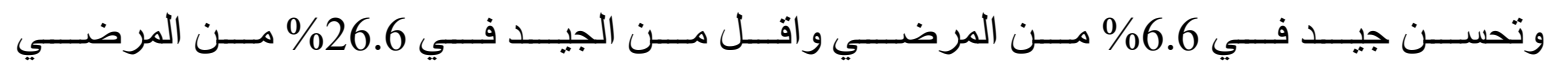

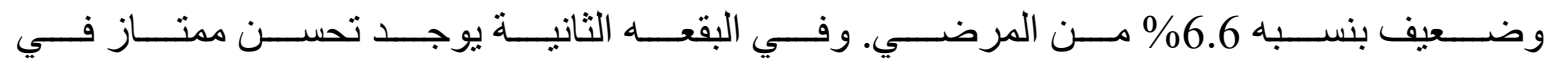

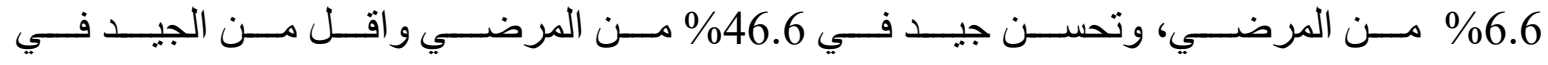
26.6\% من المرضي وضعيف بنسبه 20\% من من المرضي.

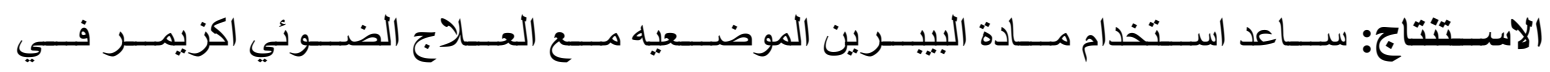

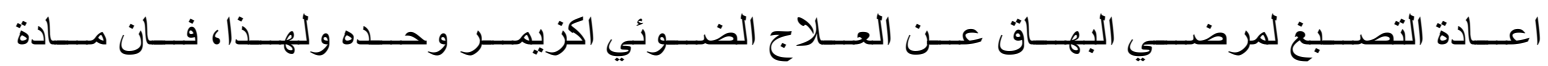
البييرين الموضعيه مع العلاج الضوئي اكزيمر يمثل علاجا واعدا في علاج البهاق. 